\title{
Antidepressant like activity of Buspirone but not of ondansetron when administered in combination with Fluoxetine or Desipramine in mice
}

\author{
Veena Verma*, Biswadeep Banerjee, Ashish K. Mehta
}

Department of Pharmacology, Vardhaman Mahavir Medical College and Safdarjung Hospital, New Delhi, India

\author{
Received: 28 February 2021 \\ Revised: 08 April 2021 \\ Accepted: 09 April 2021 \\ *Correspondence: \\ Dr. Veena Verma, \\ Email: veenaverma663@gmail.com
}

Copyright: (C) the author(s), publisher and licensee Medip Academy. This is an open-access article distributed under the terms of the Creative Commons Attribution Non-Commercial License, which permits unrestricted non-commercial use, distribution, and reproduction in any medium, provided the original work is properly cited.

\begin{abstract}
Background: The involvement of one or more 5-HT receptor sub-types in the pathophysiology of depression is still unclear. The study was performed to investigate the effect of ondansetron and buspirone on depression, and their interaction with fluoxetine or desipramine.

Methods: The mice were administered ondansetron, buspirone alone and in combinations with fluoxetine or desipramine for 21 days, and the antidepressant effect was assessed by the immobility period and the sucrose consumption, on the tail suspension test (TST) and the chronic mild stress (CMS) models, respectively.

Results: Both ondansetron and buspirone when given alone demonstrated slight non-significant decrease in the immobility time in TST model. Ondansetron when given in combination with fluoxetine $(10 \mathrm{mg} / \mathrm{kg}$; i.p.) and desipramine $(15 \mathrm{mg} / \mathrm{kg}$; i.p.), showed significant decrease in immobility time in comparison to the control group only. On the other hand, both the combinations of buspirone, either with fluoxetine or desipramine showed significant decrease in the immobility time when compared to the respective group. In CMS, the fluoxetine, desipramine, ondansetron, and buspirone showed gradual increase in the sucrose consumption, at the end of 4th, 5th, and 6th week, but the significant effect was observed only at the end of 6th week, as compared to the control. The combination of buspirone with desipramine but not with fluoxetine showed significant increase in sucrose consumption when compared to respective group.

Conclusions: Therefore, the study indicates that both buspirone and ondansetron have a potential antidepressant like action, although buspirone has shown better antidepressant activity than ondansetron as observed in various combination groups.
\end{abstract}

Keywords: Ondansetron, Buspirone, Desipramine, Fluoxetine, Tail suspension test, Chronic mild stress

\section{INTRODUCTION}

Depression is the most common psychiatric disorder worldwide, with an annual incidence of $1.59 \%$ (women $1.89 \%$; men $1.10 \%) .{ }^{1}$ The exact etiopathology of depression is still unknown; however the monoamine hypothesis largely explains the cause of depression. ${ }^{2}$ The existing antidepressants including tricyclic antidepressants (TCAs), selective serotonin reuptake inhibitors (SSRIs), and monoamine oxidase inhibitors (MAOIs), are also based on monoamine hypothesis suggesting that these drugs act by increasing the levels of biogenic amines at the synaptic cleft. In comparison to TCAs and MAOIs, SSRIs became more clinically successful because they reduce the frequency and severity of side effects that were potentially harmful, and often required withdrawal from the treatment. SSRIs selectively blocks 5-HT transport, thereby increasing the extracellular concentration of 5-HT at all postsynaptic receptors. ${ }^{3}$ Thus, multiple 5-HT receptors participation contribute towards the effect of SSRIs in treating depression and anxiety, however it is not clear which one is more important than another. Furthermore, some 5-HT receptors have become attractive 
targets for the development of novel antidepressants, which can be used either alone or in combination with other drugs, leading to more beneficial effects and less side effects than the SSRIs. ${ }^{2}$

In recent years, there has been much interest in the therapeutic potential of serotonin type 3 (5-HT3) receptor antagonists, and 5-HT1A agonist for psychiatric disorders mainly depression. ${ }^{4}$ Serotonin $(5-\mathrm{HT} 3)$ receptors are the only ligand-gated ion channel of the 5-HT receptor family..$^{5}$ They are present both in the peripheral and central nervous system, and are localized in several areas involved in mood regulation (example- hippocampus or prefrontal cortex). ${ }^{5}$ Moreover, they are involved in regulation of neurotransmitter systems implicated in the pathophysiology of major depression (example- dopamine or GABA). ${ }^{6,7}$ Several preclinical studies have suggested that targeting specific 5-HT receptors with selective agonist or antagonist drugs, either alone or in combination with other antidepressants, may enhance the antidepressant response, or it may also reduce the therapeutic delay as compared to currently used antidepressants. ${ }^{6}$ Poncelet and co-workers demonstrated that the selective 5-HT3 receptor agonist SR57227A produces antidepressant-like effect in different behavioral tests (forced swim test, learned helplessness) in rodents. ${ }^{8}$ In contrast, other investigators have observed that 5-HT3 receptor agonists when administered alone or in combination with antidepressants were ineffective in the forced swimming test, while another study reported that 5HT3 receptor agonists attenuate the effects of antidepressants in the same animal model. ${ }^{9}$ Besides 5HT3, agonists of the 5-HT1A receptor have been shown to produce an antidepressant response through mediation of postsynaptic binding sites, possibly through alteration of second messenger transduction. ${ }^{10}$

Moreover, due to the conflicting results of various preclinical studies, the role of 5-HTreceptors is still not yet clearly defined in depression. Therefore, in view of this, the present study was conducted with the aim to investigate the antidepressant like activity of Ondansetron and Buspirone, and to evaluate their interaction with fluoxetine and desipramine in two animal models of depression, namely the tail suspension test (TST), and chronic mild stress (CMS), both of which have high validity and specificity. ${ }^{11}$

\section{METHODS}

\section{Animals}

Swiss albino male mice weighing between $22-25 \mathrm{~g}$ were utilized for this study. The animals were housed in standard laboratory conditions (12-h light/dark cycle, $21 \pm 1^{\circ} \mathrm{C}$, and relative humidity of $55 \pm 5 \%$ ), with free access to food and water. After 7 days of acclimatization to laboratory conditions, the animals were randomly assigned to different groups, each consisting of 6-8 mice. Each animal was used only once in the experimental procedures.
All experiments were carried out between 0900 and 1600 h. The control group was studied concurrently with the experimental groups. The study was conducted in the Department of Pharmacology, VMMC and Safdarjung Hospital, New Delhi, India, after being approved by the Institutional Animals Ethics Committee. The study procedures were carried out in accordance with the CPCSEA Guidelines for the Care and Use of Laboratory Animals.

\section{Drugs and chemicals}

Ondansetron, fluoxetine, buspirone and desipramine were procured from Sigma-Aldrich, India, while 1\% Sucrose and $0.9 \%$ saline were obtained from the departmental store. All the drugs were freshly prepared by dissolving the pure powder in the distilled water before administration.

\section{Study design}

Single dose of fluoxetine $(10 \mathrm{mg} / \mathrm{kg})$, desipramine (15 $\mathrm{mg} / \mathrm{kg})$, buspirone $(0.5 \mathrm{mg} / \mathrm{kg})$, and ondansetron $(0.1$ $\mathrm{mg} / \mathrm{kg}$ ) was administered intraperitoneally (i.p.) daily for 21 days. The control group received appropriate vehicle. For the interaction studies, ondansetron (in the same dose) was combined and administered either with fluoxetine or desipramine. In the TST model, the immobility time was measured on 22nd day, while in the CMS model, the drug administration and sucrose consumption test was carried out after 3rd week of stress induction. Sucrose consumption test was performed weekly on day 28, 35 and 42. The doses of all the drugs were selected on the basis of pilot experiments and previous studies from the literature.

\section{Behavioral tests}

\section{Tail suspension test}

In this model, the total duration of immobility induced by tail suspension was measured. ${ }^{12}$ Mice were both acoustically and visually isolated and suspended $50 \mathrm{~cm}$ above the floor by adhesive tape placed approximately 1 $\mathrm{cm}$ from the tip of the tail. Immobility time was observed during a 6 min period, and recordings were made as the number of seconds the animal remains immobile. Mice were considered immobile only when they were completely motionless. Animals were treated with the drugs and their combinations for 21 days, and thereafter TST was carried out on the 22nd day.

\section{CMS}

Animals were randomly separated into groups, as shown in Table 1. The CMS procedure was a variation of methods described previously. ${ }^{13}$ Animals were first trained to consume a $1 \%$ sucrose solution. The training consisted of a test where sucrose was presented in the home cage, following $14 \mathrm{~h}$ of food and water deprivation. Sucrose intake was measured by weighing pre-weighed bottles containing the sucrose solution, at the end of the test. 
Subsequently, sucrose consumption was monitored, under similar condition at weekly intervals throughout the experiment. Animals were subjected to the CMS procedure for a period of 3 consecutive weeks. Each week of the stress regime consisted of two periods of food or water deprivation; two periods of intermittent illumination (lights on and off every 2 hours); two periods of 45 degree cage tilt; two periods of soiled cage $(250 \mathrm{ml}$ water in sawdust bedding); two periods of paired housing; two periods of low intensity stroboscopic illumination (150 flashes/min) and two periods of no stress. All stressors were $10-14 \mathrm{~h}$ of duration, and were applied individually and continuously, day and night. The sucrose consumption test was carried out at 10 AM every Tuesday for $24 \mathrm{~h}$ during 3 weeks treatment period after stress induction. Increase in sucrose consumption is compared with control group and expressed as mean $\pm \mathrm{SD}$.

\section{Statistical analysis}

The results were expressed as mean $\pm \mathrm{SD}$ of $\mathrm{n}$ (number of animals studied) observations. The results were analyzed by one way ANOVA followed by Dunnetts's post hoc test where $p<0.05$ was considered statistically significant.

\section{RESULTS}

\section{Effect of fluoxetine, desipramine, buspirone, ondansetron, and their combinations on TST}

Both fluoxetine (10 mg/kg; i.p.) and desipramine (15 $\mathrm{mg} / \mathrm{kg}$; i.p.) significantly reduced the immobility time, and increased the duration of struggle compared to the control group in TST, thereby suggesting an antidepressant like action $(p<0.05)$ (Table 1). On the other hand, both ondansetron and buspirone per se demonstrated slight decrease in the immobility time that was not statistically significant. Both fluoxetine $(10 \mathrm{mg} / \mathrm{kg}$; i.p. $)$ and desipramine (15 mg/kg; i.p.) when combined with ondansetron $(0.1 \mathrm{mg} / \mathrm{kg}$; i.p.) showed significant decrease in immobility time, and increase in duration of struggle as compared to the control. However, when compared to the respective group, only ondansetron + fluoxetine group showed decrease in the immobility time in comparison to the fluoxetine group although it was not found to be statistically significant. On the other hand, both the combinations of buspirone, either with fluoxetine or desipramine showed significant decrease in the immobility time when compared to the respective group.

\section{Effect of fluoxetine, desipramine, buspirone, ondansetron, and their combinations on CMS}

The CMS model involves infliction of various stressors like tilting of cages, periods of food and water withdrawal, etc. for the first 3 weeks. CMS caused a gradual decrease in the consumption of $1 \%$ sucrose solution towards the end of 3 weeks, thereby suggesting the development of depression (Table 2).
Table 1: Effect of fluoxetine, desipramine, ondansetron, buspirone, and their combinations on the immobility period of mice in the tail suspension test. The data are expressed as Mean \pm S.D. $* p<0.05$ versus control; ${ }^{a} \mathrm{p}<0.05$ versus fluoxetine; ${ }^{\mathrm{b}} \mathrm{p}<0.05$ versus desipramine.

\begin{tabular}{|ll|}
\hline Groups & $\begin{array}{l}\text { Period of immobility } \\
\text { (in s) }\end{array}$ \\
\hline Control & $182.00 \pm 8.48$ \\
\hline Fluoxetine & $146.17 \pm 11.46^{*}$ \\
\hline Desipramine & $147.83 \pm 10.99^{*}$ \\
\hline Ondansetron & $166.50 \pm 6.05$ \\
\hline Buspirone & $171.00 \pm 2.58$ \\
\hline Ondansetron+Fluoxetine & $126.17 \pm 7.30^{*}$ \\
\hline Ondansetron+Desipramine & $146.17 \pm 11.46^{*}$ \\
\hline Buspirone + Fluoxetine & $124.67 \pm 9.52^{* a}$ \\
\hline Buspirone + Desipramine & $124.00 \pm 7.48^{* b}$ \\
\hline
\end{tabular}

Table 2: Effect of fluoxetine, desipramine, ondansetron, buspirone, and their combinations on the sucrose preference test in mice. The data are expressed as Mean \pm S.D. * $\mathbf{p}<0.05$ as compared to the control; ${ }^{\mathrm{a}} \mathrm{p}<0.05$ as compared to desipramine.

\begin{tabular}{|llll|}
\hline & \multicolumn{3}{c}{ Sucrose consumption $(\mathrm{g} / \mathrm{kg})$} \\
\hline $\begin{array}{l}\text { Groups } \\
\text { Non-stressed }\end{array}$ & $16.9 \pm 0.3$ & $16.9 \pm 0.3$ & $16.9 \pm 0.3$ \\
$\begin{array}{l}\text { CMS+ Saline } \\
\text { (Control) }\end{array}$ & $8.3 \pm 0.8$ & $9.2 \pm 0.7$ & $10.7 \pm 0.6$ \\
\hline $\begin{array}{l}\text { CMS+ } \\
\text { Fluoxetine (F) }\end{array}$ & $10.9 \pm 0.7$ & $13.4 \pm 0.5$ & $15.9 \pm 0.4^{*}$ \\
\hline $\begin{array}{l}\text { CMS+ } \\
\text { Desipramine (D) }\end{array}$ & $11.4 \pm 0.7$ & $13.4 \pm 0.5$ & $15.0 \pm 0.5^{*}$ \\
\hline $\begin{array}{l}\text { CMS+ } \\
\text { Ondansetron (O) }\end{array}$ & $9.5 \pm 0.6$ & $11.0 \pm 0.6$ & $12.5 \pm 0.5^{*}$ \\
\hline $\begin{array}{l}\text { CMS + } \\
\text { BuSpirone (B) }\end{array}$ & $8.8 \pm 0.5$ & $10.3 \pm 0.3$ & $12.1 \pm 0.6^{*}$ \\
\hline CMS + (O+F) & $12.0 \pm 0.4$ & $14.5 \pm 0.5$ & $16.3 \pm 0.6^{*}$ \\
\hline CMS + (O+ D) & $11.3 \pm 0.6$ & $13.9 \pm 0.7$ & $16.3 \pm 0.3^{* a}$ \\
\hline CMS + (B+ F) & $12.2 \pm 0.5$ & $13.9 \pm 0.7$ & $16.5 \pm 0.2^{*}$ \\
\hline CMS + (B + D) & $11.2 \pm 0.5$ & $14.7 \pm 0.6$ & $16.8 \pm 0.2^{* a}$ \\
\hline
\end{tabular}

Thereafter, the drugs were administered for the next 3 weeks, and the sucrose consumption was measured each week. Only the results of SPT conducted at the end of 4th, 5 th and 6th week were considered for the study as the drugs were administered after end of 3rd week, and also no significant conclusion can be drawn from the SPT of first three weeks.

All the 4 groups, i.e., fluoxetine $(10 \mathrm{mg} / \mathrm{kg})$; desipramine $(15 \mathrm{mg} / \mathrm{kg})$; ondansetron $(0.1 \mathrm{mg} / \mathrm{kg})$ and buspirone $(0.5$ $\mathrm{mg} / \mathrm{kg}$ ) showed gradual increase in the sucrose consumption, at the end of 4th, 5th, and 6th week, but the significant effect was observed only at the end of 6 th week, as compared to the control $(\mathrm{p}<0.05)$. The combination of fluoxetine $(10 \mathrm{mg} / \mathrm{kg})$ and desipramine with ondansetron $(0.1 \mathrm{mg} / \mathrm{kg})$ showed a significant increase in sucrose 
consumption when compared with control group, and also respective desipramine group $(\mathrm{p}<0.05)$, but not when compared with respective fluoxetine. Similarly, combination of buspirone with desipramine showed significant increase in sucrose consumption when compared to respective desipramine group; however, the significant increase was not observed with fluoxetine combination in comparison to the respective group.

\section{DISCUSSION}

Major depression is one of the most widespread psychiatric illnesses. It is an important public health problem since major depression induces disability, poor quality of life, economic burden or suicide. According to the monoaminergic theory of depression, deficiencies or imbalances in monoamine neurotransmitters, i.e., serotonin (5-HT), noradrenaline (NA) and dopamine (DA), are involved in the pathophysiology of this disease. ${ }^{14}$ Development of antidepressants in the last five decades has been mainly based on this hypothesis. The SSRIs such as fluoxetine have been shown to be of major benefit in the treatment of depression by enhancing the synaptic 5HT levels. ${ }^{15}$ The mechanism by which the elevation of synaptic concentration of 5-HT alleviates the symptoms of depression is not known but the involvement of multiple 5HT receptor subtypes would appear to be obvious factor. Furthermore, several preclinical studies have suggested that targeting specific 5-HT receptors with the selective agonist or antagonist may enhance the antidepressant response, and reduce its delay compared to currently used antidepressants. ${ }^{16}$ However, it is still not clear which 5-HT receptor subtype is more important than others.

In the present study, we have used buspirone (5HT1A agonist) and ondansetron (5HT3 antagonist) to investigate their possible antidepressant action in two animal models of depression, the TST and CMS, and their interaction with the standard antidepressants, i.e., the fluoxetine and desipramine. Both of these models are widely used to screening of newer and potential antidepressant drugs. A significant correlation has been observed between the potency of antidepressants in the TST and CMS tests, and the clinical potency of the drugs. ${ }^{17}$ These tests are quite sensitive and relatively specific to all major classes of antidepressants like tricyclics, SSRIs, monoamine oxidase (MAO) inhibitors, and atypicals.

In the present study, both buspirone $(0.5 \mathrm{mg} / \mathrm{kg})$ and ondansetron $(0.1 \mathrm{mg} / \mathrm{kg})$ when administered per se, did not significantly decrease the immobility time. This finding is similar to an earlier study where it was observed that this antidepressant-like effect of 8-OH-DPAT (3 mg/kg, s.c.) (assessed by its ability to decrease the immobility time in forced swim test) was mimicked by ipsapirone, but not buspirone or gepirone; despite these drugs being selective 5HT1A agonist, and all of which have been reported to possess antidepressant activity. ${ }^{18}$ Further, these three compounds did not demonstrate a consistent effect in forced swim test in rats. However, Wieland and Lucki reported that ipsapirone, buspirone and gepirone each induced an antidepressant like effect, although only after subcutaneous administration of relatively high doses (20 $\mathrm{mg} / \mathrm{kg}) .{ }^{19} \mathrm{In}$ contrast, Przegalinski and co-workers reported that ipsapirone and buspirone were both ineffective, although they did find a relatively potent antidepressant like effect with gepirone with both treatment schedules. ${ }^{20}$ This can be attributed to the fact that buspirone acts as a partial agonist at the postsynaptic 5HT1A receptors, while the compound 8-OH-DPAT acts as a full agonist at the 5HT1A receptor, and hence shows a significant response. ${ }^{18}$

Moreover, in the present study, ondansetron at a dose of $0.1 \mathrm{mg} / \mathrm{kg}$ did not show antidepressant like action, which were contrary to the effects observed in an earlier study wherein it was found that ondansetron $(0.5-2 \mathrm{mg} / \mathrm{kg}$, i.p.) reduced the immobility time in mice in the FST. ${ }^{16}$ The possible explanation for such varied result is that the involvement of 5-HT3 receptors is complex and their molecular structure, function and regulation are only partially elucidated. Further, the various 5HT3 antagonists showed a bell-shaped dose response curve in preclinical studies. ${ }^{6}$ Moreover, in the present study, we have used only a single dose of ondansetron and buspirone due to the constraint on the number of animals for performing the experiments. Therefore, further dose range studies with higher doses are needed to be performed to evaluate the antidepressant action of ondansetron and buspirone in TST model.

In the interaction studies, it was found that all combination groups, i.e., buspirone+ fluoxetine, ondansetron + fluoxetine, buspirone +desipramine, and ondansetron+ desipramine decreased the immobility time significantly when compared to the control. On comparison with the positive control (fluoxetine group), the buspirone+ fluoxetine group decreased the immobility time significantly $(\mathrm{p}<0.05)$, while the ondansetron + fluoxetine group did not cause significant decrease in the immobility time. Similarly, buspirone + desipramine reduced the immobility time significantly as compared to desipramine alone, but significant antidepressant effect was not observed with the ondansetron+ desipramine group. This finding is similar to the one, observed by Luscombe and co-workers wherein 8-OH-DPAT (5HT1a receptor agonist) in a dose of $3 \mathrm{mg} / \mathrm{kg}$, s.c. was found to augment the effect of desipramine $(3-30 \mathrm{mg} / \mathrm{kg}$, s.c.) in the FST paradigm. ${ }^{18}$ These findings suggest that buspirone has a more significant role in augmenting the antidepressant effect of both fluoxetine and desipramine as compared to ondansetron.

Chronic sequential exposure of mice to a variety of mild stressors produces overall increase in depressive behaviours in rats and mice, which appear similar to human depression. $^{21,22}$ The most common behavioral change measured during CMS experiment is the presence of anhedonia represented by decreased consumption of $1 \%$ sucrose solution. The alteration caused by CMS has been demonstrated to be reversed by chronic treatment with 
traditional antidepressant drugs, desipramine and fluoxetine. ${ }^{23}$ In the present study, both buspirone and ondansetron significantly increased the sucrose consumption at the end of the 6thweek, as compared to the control group. Further, all combinations, i.e., fluoxetine+ buspirone; fluoxetine+ ondansetron; desipramine+ buspirone, and desipramine+ ondansetron significantly increased the sucrose consumption as compared to the control. However, in comparison to the respective group, both the combinations of fluoxetine either with ondansetron or buspirone did not show significant increase in the sucrose consumption. However, both the combinations of desipramine either with buspirone or desipramine showed significant increase in sucrose consumption, in comparison to respective group. These findings reveal that both buspirone and ondansetron have the ability to enhance the antidepressant effect of desipramine but not fluoxetine. Similar result was observed by Redrobe and co-workers wherein it was observed that the 5HT1A agonist 8-OH-DPAT (1 mg/kg, i.p.) induced anti-immobility effect with tricyclic antidepressant desipramine $(16 \mathrm{mg} / \mathrm{kg}$, i.p.) but not with fluoxetine (16 $\mathrm{mg} / \mathrm{kg}$, i.p. .). ${ }^{24}$ This can be attributed to the fact that the antidepressant effect of selective serotonin reuptake inhibitors (fluoxetine) seem to be mediated by presynaptic 5-HT1A receptors as well as postsynaptic 5-HT1B receptors whereas the antidepressant effect of noradrenaline uptake inhibitors (desipramine) seem to be mediated by postsynaptic 5-HT1A receptors, and hence their effect is enhanced by co-administration of buspirone (a 5HT1A agonist). ${ }^{16}$ Moreover, as the etiology of depression has not yet been fully elucidated and involves the interplay of various neurotransmitters like serotonin, noradrenaline, dopamine, BDNF, and perhaps GABA at various brain sites including hippocampus and prefrontal cortex, one cannot fully comprehend the effects of various drugs and their combinations. 6 Therefore, further studies with newer agonist and antagonists of 5-HT receptors are needed to exactly define their role in depression.

\section{CONCLUSION}

The present study indicates that both buspirone and ondansetron alone and in combination with fluoxetine or desipramine have a potential antidepressant like action although buspirone showed better antidepressant activity than ondansetron as seen in various combination groups. Their effect could be attributed to the enhanced serotonergic activity probably at 5-HT1A and 5-HT3 receptors. However, as the combination of buspirone with fluoxetine or desipramine showed better antidepressant like action than the combinations of ondansetron in both the models, therefore suggesting more important role of 5HT1A receptor in depression.

Funding: No funding sources Conflict of interest: None declared

Ethical approval: The study was approved by the Institutional Animal Ethics Committee

\section{REFERENCES}

1. Sadock BJ, Sadock VA. Kaplan and Sadock's Synopsis of Psychiatry, 10th edition. 2007: 527-528.

2. Hindmarch I. Expanding the horizons of depression beyond the monoamine hypothesis. Hum Psychopharmacol. 2001;16:203-18.

3. Ceglia I, Acconcia S, Fracasso C, Colovic M, Caccia $\mathrm{S}$, Invernizzi RW. Effects of chronic treatment with escitalopram or citalopram on extracellular 5-HT in the prefrontal cortex of rats: role of 5-HT1A receptors. Br J Pharmacol. 2004;142:469-78.

4. Rajkumar R, Mahesh R. The auspicious role of the 5HT3 receptor in depression: a probable neuronal target? J Psychopharmacol. 2010;24:455-69.

5. Barnes NM, Sharp T. A review of central 5-HT receptors and their function. Neuropharmacology. 1999;38:1083-152.

6. Bétry C, Etiévant A, Oosterhof C, Ebert B, Sanchez C, Haddjeri N. Role of 5-HT3 receptors in the antidepressant response. Pharmaceuticals. 2011;4:603-29.

7. Yohn CN, Gergues MM, Samuels BA. The role of 5HT receptors in depression. Mol Brain. 2017;10:28.

8. Poncelet M, Perio A, Simiand J, Gout G, Soubrie P, Le Fur G. Antidepressant-like effectsof SR 57227A, a 5-HT3 receptor agonist, in rodents. J Neural Transm Gen Sect. 1995;102:83-90.

9. Redrobe JP, Bourin M. Partial role of 5-HT2 and 5HT3 receptors in the activity of antidepressants in the mouse forced swimming test. Eur $\mathrm{J}$ Pharmacol. 1997;325:129-35.

10. Patrick M, Richard JB, Michel H, Alain JP. Antidepressant-like action of 8-OH-DPAT, a 5-HT1A agonist, in the learned helplessness paradigm: evidence for a postsynaptic mechanism. Behav Brain Res. 1990;38:135-44.

11. Willner P. Validity, reliability and utility of the chronic mild stress (CMS) model of depression: A tenyear review and evaluation. (Plus 17 peer commentaries and author's response). Psychopharmacology. 1997;134:319-77.

12. Steru L, Chermat R, Thierry B, Simon P. The tail suspension test: a new method for screening antidepressants in mice. Psychopharmacology (Berl). 1985;85:367-70.

13. Sánchez C, Gruca P, Papp M. R-citalopram counteracts the antidepressant-like effect of escitalopram in a rat chronic mild stress model. Behav Pharmacol. 2003;14:465-70.

14. Nutt DJ. Relationship of neurotransmitters to the symptoms of major depressive disorder. J Clin Psychiatry. 2008;69:E1:4-7.

15. Goodnick PJ. Use of antidepressants in treatment of co-morbid diabetes mellitus and depression as well as in diabetic neuropathy. Ann Clin Psychiatry. 2001;13:31-41.

16. Radhakrishnan M, Viyogi S, Pandey DK, Yadav S. Evaluation of anti-depressant and analgesic-like activity of Ondansetron in a rodent model of co- 
morbid pain and depression. Indian J Pharm Educ Res. 2010;44.

17. Bourke $\mathrm{CH}$, Stowe $\mathrm{ZN}$, Owens MJ. Prenatal antidepressant exposure: clinical and preclinical findings. Pharmacol Rev. 2014;66:435-65.

18. Luscombe GP, Martin KF, Hutchins LJ, Gosden J, Heal DJ. Mediation of the antidepressant-like effect of 8-OH-DPAT in mice by postsynaptic 5-HT1A receptors. Br J Pharmacol. 1993;108:669-77.

19. Wieland S, Lucki I. Antidepressant-like activity of 5HT1A agonists measured with the forced swim test. Psychopharmacology (Berl). 1990;101:497-504.

20. Przegaliński E, Tatarczyńska E, Kłodzińska A, Chojnacka-Wójcik E. The role of postsynaptic 5HT1A receptors in the anticonflict effect of ipsapirone. Neuropharmacology. 1994;33:1109-15.

21. Qiao Y, Zhao J, Li C, Zhang M, Wei L, Zhang X, Kurskaya O, Bi H, Gao T. Effect of combined chronic predictable and unpredictable stress on depression-like symptoms in mice. Ann Transl Med. 2020;8:942.
22. Wang Q, Timberlake MA 2nd, Prall K., Dwivedi Y. The recent progress in animal models of depression. Prog Neuropsychopharmacol Biol Psychiatry. 2017;77:99-109.

23. Muscat R, Papp M, Willner P. Reversal of stressinduced anhedonia by the atypical antidepressants, fluoxetine and maprotiline. Psychopharmacology. 1992;109:433-8.

24. Redrobe JP, MacSweeney CP, Bourin M. The role of 5HT1a and 5HT1b receptors in antidepressant drug actions in the mouse forced swimming test. Eur $\mathbf{J}$ Pharmacol. 1996;318:213-20.

Cite this article as: Verma V, Banerjee B, Mehta AK. Antidepressant like activity of Buspirone but not of ondansetron when administered in combination with Fluoxetine or Desipramine in mice. Int J Basic Clin Pharmacol 2021;10:621-6. 